\title{
Validation of the Brazilian version of the Spinal Cord Independence Measure III
}

\author{
Validação da versão brasileira da Medida de Independência da Medula Espinhal III \\ Marcelo Riberto', Daniel Amorim Tavares², José Ragide Jamal Rimoli, Carolina Pastorin Castineira ${ }^{2}$, \\ Rodrigo Vasconcelos Dias ${ }^{1}$, Ana Cristina Franzoi ${ }^{3}$, Janaina Vall ${ }^{4}$, Kathya Augusta Thomé Lopes ${ }^{5}$, Regina \\ Helena M Fornari Chueire ${ }^{6}$, Linamara Rizzo Battistella²
}

\begin{abstract}
Introduction: The Spinal Cord Independence Measure (SCIM III) specifically assesses individuals with spinal cord injuries. Objective: To translate and validate the Brazilian version of SCIM III. Method: SCIM III was translated, back-translated and adapted to the Portuguese language. Two interviewers assessed 83 subjects with spinal cord injuries in each one of seven collaborating rehabilitation centers. Functional Independence Measure (FIM ${ }^{T M}$ ) and ASIA motor and sensory indices were also used. After six months, subjects were reevaluated with the same instruments. Results: Examiners clearly understood the Brazilian version of SCIM III. Inter-rater intraclass correlation coefficient (ICC) was 0.918, and test-retest ICC was 0.991. After six months, the variation of gains in the FIM ${ }^{\text {TM }}$ positively correlated with gains in SCIM III. Conclusion: The Brazilian version of the SCIM III is easy to understand, has good psychometric properties, and is valid.
\end{abstract}

Keywords: spinal cord, Spinal Cord Independence Measure, validation.

\section{RESUMO}

Introdução: A Medida de Independência da Medula Espinhal III (SCIM III) avalia especificamente a funcionalidade de indivíduos com lesões da medula espinhal. Objetivo: Traduzir e validar a versão brasileira da SCIM III. Método: A SCIM III foi traduzida, contra-traduzida e adaptada para o idioma português brasileiro. Dois entrevistadores avaliaram 83 indivíduos com lesões da medular espinhal em sete centros de reabilitação colaboradores. A Medida de Independência Funcional (FIM ${ }^{\top M}$ ) e índices motor e sensitivo da ASIA também foram usados. Após seis meses, os sujeitos foram reavaliados com os mesmo instrumentos. Resultados: Os avaliadores entenderam claramente a versão brasileira da SCIM III. O coeficiente de correlação intraclasse (ICC) inter-examinadores foi 0,918, e de teste-reteste foi 0,991. Após seis meses, a variação de ganhos na FIM ${ }^{\top \mathrm{M}}$ correlacionou-se positivamente com os ganhos da SCIM III. Conclusão: A versão brasileira da SCIM III é de fácil entendimento, apresenta boas propriedades psicométricas e é válida.

Palavras-chave: medula espinhal, Medida de Independência da Medula Espinhal, validação.

Temporary or permanent loss of motor, sensory, and autonomic functions caused by spinal cord injury create a series of consequences on functioning, whether related to physiological functions, structural changes in the body, or to difficulties in activities and participation ${ }^{1,2}$. Many aspects of the activities and participation can be evaluated, such as precision of movements, time required to execute them, and the occurrence and severity of errors. How- ever, the final outcome for most rehabilitation services is functional independence ${ }^{3}$, for this is related to personal values, family determinants ${ }^{4,5}$, and is usually associated with social participation, especially in less developed countries where environmental factors act predominantly as barriers ${ }^{6}$.

The first scales to measure such damage focused mainly in physical examination and radiological imaging. However,

${ }^{1}$ Faculdade de Medicina de Ribeirão Preto, Ribeirao Preto SP, Brazil;

Universidade de São Paulo, Sao Paulo SP, Brazil;

${ }^{3}$ Universidade Federal do Rio de Janeiro, Rio de Janeiro RJ, Brazil;

«Universidade Federal do Ceará, Fortaleza CE, Brazil;

${ }^{5}$ Universidade Federal do Amazonas, Manaus AM, Brazil;

${ }^{6}$ Instituto de Reabilitação Lucy Montoro de São José do Rio Preto, Sao Jose do Rio Preto SP, Brazil.

Correspondence: Marcelo Riberto; Faculdade de Medicina de Ribeirão Preto - Biomecânica, Medicina e Reabilitação do Aparelho Locomotor; Avenida Bandeirantes 3900; 14049-900 Ribeirão Preto SP, Brasil. E-mail: mriberto@usp.br

Conflict of interest: There is no conflict of interest to declare.

Received 06 December 2013; Received in final form 25 February 2014; Accepted 18 March 2014. 
these measurements did not always correlate well with functioning and well-being. Currently, the subject's quality of life and self-perception of improvement has been emphasized due to the possibility of analyzing the general state of health and providing information for the evaluation of different therapeutic interventions.

Some questionnaires incorporate specific characteristics of disability, such as motor and sensory aspects, and difficulties in performing daily life activities. The most wellknown and currently-used questionnaires related to functioning in general are not specific for individuals with spinal cord injuries, and they include: the Functional Independence Measure (FIM $\left.{ }^{\mathrm{TM}}\right)$, especially its motor component, the Barthel Index, the Satisfaction with Life scale, the Craig Handicap and Reporting Technique, and the Japanese Orthopedic Association scale ${ }^{7}$, as well as generic scales for quality of life such as the 36-Item Short Form Health Survey (SF-36), the World Health Organization Quality of Life Assessment (WHOQoL), the Sickness Impact Profile (SIP), and the Euro-QoL (EQ-5D) .

The core set from the International Classification of Functionality, Disability, and Health (ICF) for spinal cord injury has recently been published, which broadly describes functioning of people with spinal cord injuries, and also considers the role of environmental factors either as barriers or facilitators ${ }^{2}$. In addition to this instrument, the Walking Index for Spinal Cord Injury (WISCI) ${ }^{10}$ and the Spinal Cord Independence Measure (SCIM) ${ }^{11}$ must be mentioned, for they are specific for spinal cord injury. Especially the SCIM, now in its third version - SCIM III ${ }^{12}$, which is directed to the ability to perform tasks, approaches the aspects inherent to spinal cord injury, being able to detect improvement in aspects such as breathing, ability to change body position, and gait, with distinct properties from the $\mathrm{FIM}^{\mathrm{TM}}$.

Based on their clinical experiences, the authors understand that the SCIM III can be a valuable instrument to manage the rehabilitation process of the individual with spinal cord injury and the objective of this study is to translate the instrument into the Portuguese spoken in Brazil, validate it comparatively to the $\mathrm{FIM}^{\mathrm{TM}}$, test its reproducibility, and evaluate its sensitivity to clinical changes undergone by individuals with traumatic spinal cord injuries.

\section{METHOD}

This is an observational multicenter study, with a face validity cross-sectional phase, testing for reliability and a comparison with other evaluation instruments, along with a longitudinal evaluation of sensitivity to clinical changes. It was approved by the committees for ethics in research from all the participating institutions, and the study subjects were only included after signing a Free and Informed Consent Form.

\section{SCIM III - translation process - face validity}

The SCIM III assesses levels of independence to perform daily life activities and mobility for individuals with spinal cord injury. It is divided into three supplementary sub-scales: "self-care" evaluates six tasks and is scored from 0 to 20; "breathing and sphincter control" (scored from 0 to 40) with four tasks, and "mobility" (scored from 0 to 40) with nine tasks. The final score varies from 0 (more dependent) to 100 (more independent). The SCIM III must be applied by a professional who is familiar with the instrument and with the rehabilitation of individuals with spinal cord injury, although no previous training is recommended. Answers can be obtained by interviews or direct observation of the subject while performing the numbered tasks; the health professional doing the measuring must search for the information closest to the level of independence of the individual in his or her daily life. It became a standard that when the individual had two different levels of independence for some task, depending on the time of the day or other contextual factors, the lower level would prevail when deciding the final score.

The translation of the original version of the SCIM III into Portuguese was made according to the recommendations in the literature ${ }^{13}$. Initially, two versions in Portuguese (Va and $\mathrm{Vb}$ ) were created by two independent translators: one with medical knowledge and the other a lay person. From those two versions, a synthesized version (Vc) was approved by a committee formed by specialists in the area. This version (Vc) was independently back-translated into English by two certified translators (Vd and Ve) and compared to verify inconsistencies with the original version in English.

These versions ( $\mathrm{Vd}$ and $\mathrm{Ve}$ ) were then compared with the original version by two bilingual specialists in the area of rehabilitation to once again verify inconsistencies. Subsequently, to test this version, 10 health professionals used to treating individuals with spinal cord injuries were asked to give their impressions about the terms used in the final version. The final product is the Brazilian version of the SCIM III being tested in this study.

\section{Field tests}

In order to test the SCIM III in comparison with other evaluation instruments already established for the functional assessment of individuals with spinal cord injuries, research subjects from seven Brazilian rehabilitation centers were recruited: The Associação Brasileira Beneficente de Reabilitação (Brazilian Beneficent Association for Rehabilitation - ABBR) in Rio de Janeiro, the Instituto de Ortopedia e Traumatologia (Orthopedics and Traumatology Institute), and the Instituto de Medicina Física $e$ 
Reabilitação do Hospital das Clínicas, Faculdade de Medicina, Universidade de São Paulo (Physical Medicine and Rehabilitation Institute from the HC-FMUSP) in São Paulo, the Instituto de Reabilitação Lucy Montoro (Lucy Montoro Rehabilitation Institute) in São José do Rio Preto, the Instituto José Frota (José Frota Institute) in Fortaleza, the Programa de Atividades Físicas para Deficientes da Universidade Federal do Amazonas (Program of Physical Activities for the Disabled from the Federal University of Amazonas), and the Hospital das Clínicas da Faculdade de Medicina-Universidade de São Paulo (Hospital das Clinicas of the Ribeirao Preto Medical School of the University of São Paulo) in Ribeirão Preto.

The inclusion criteria in this study were:

- Subjects with traumatic spinal cord injury

- Subjects being treated in a rehabilitation center in Brazil

- Subjects agreed to participate in the study, signing a Free and Informed Consent Form

There were no exclusion criteria related to clinical, cognitive conditions or to co-morbidities.

Subjects were evaluated with the following instruments:

- The ASIA standardized evaluation: motor and sensory level of each side of the body, ASIA impairment scale (AIS), motor and sensory indices and partial preservation zone;

- The FIM ${ }^{\mathrm{TM}}$, which evaluates the level of functional independence on a scale from 1 (total dependence) to 7 (complete independence) for 13 motor activities (FIM ${ }^{\mathrm{TM}}$ motor) and 5 cognitive activities $\left(\mathrm{FIM}^{\mathrm{TM}}\right.$ cognitive), forming a final score that ranges from 18 to 126 . The FIM $^{\mathrm{TM}}$ can be applied by a trained and experienced evaluator and it is based on an interview and direct observation of the individual's performance in his or her daily life ${ }^{14}$;

- The SCIM III, described above.

In order to evaluate the inter-rater reproducibility, in each institution two evaluators with different professional backgrounds were chosen - A (more experienced) and B (less experienced) - to apply the FIM $^{\mathrm{TM}}$ and the SCIM III on the same day to the subjects recruited from each rehabilitation center. In a period ranging from two to five days, as long as the subjects of the study had not shown any relevant functional changes, the SCIM III was applied again by the most experienced researcher to evaluate the intra-rater reliability (test-retest). Individuals with evident changes in functioning for any clinical reason during these days were not interviewed again. After six months, the subjects were evaluated again with both FIM $^{\mathrm{TM}}$ and SCIM III, by only one of the evaluators, to measure sensitivity of these scales to modifications in functioning.

Descriptive analysis of data used means and standarddeviations for the quantitative variables that were compared using the Student's t-test, and percentages for the qualitative variables categories that were compared by the chi-square test. The reliability was evaluated by the intraclass correlation coefficient (ICC) for the paired observations between two evaluators and also for the test-retest, which involved only the observations of one evaluator at two different moments. In order to calculate ICC, data from both evaluators from all the institutions were integrated and considered as only one A and only one B. For sensitivity measurement, results from the first assessment were subtracted from the last evaluation, six months later, and the degrees of modification in the FIM $^{\mathrm{TM}}$ and SCIM III were compared. The Pearson's coefficient was calculated for the correlation between the quantitative variables. Significance level was 0.05 .

\section{RESULTS}

The result of this project is the Brazilian version of the SCIM III. It was well received by the group of specialists, who had no conflict about the terms employed for the items evaluated or for their possible answers. The intraclass correlation coefficient calculated for the inter-rater reliability was 0.918 , and for the test-retest, it was 0.991 .

Table 1 shows summarized biodemographic and clinical data of the study's subjects. The study included 83 subjects being treated in seven different rehabilitation centers, most of whom were in their third or fourth decade of life, paraplegic, and with complete injuries. The comparison between paraplegic and tetraplegic individuals showed no differences, except in the level of motor performance, as expected.

Figure 1 expresses a clear positive correlation between the SCIM III, on the X-axis, and the AIS motor index

Table 1. Biodemographic and clinical data

\begin{tabular}{|c|c|c|c|c|}
\hline & Total (83) & Paraplegic Individuals (52) & Tetraplegic Individuals (31) & $\mathrm{p}$ \\
\hline Age (years) & $36.1 \pm 15.4$ & $34.7 \pm 14.8$ & $35.6 \pm 14.5$ & $0.79 *$ \\
\hline Males & 68.7 & 65.4 & 74.2 & $0.33 * \star$ \\
\hline AIS A (\%) & 69.5 & 57.7 & 93.5 & $0.68 * \star$ \\
\hline $\mathrm{FIM}^{\mathrm{TM}} \mathrm{m}$ & $40.1 \pm 24.1$ & $49.7 \pm 33.4$ & $30.5 \pm 23.9$ & $<0.01^{*}$ \\
\hline $\mathrm{FIM}^{\mathrm{TM}} \mathrm{C}$ & $33.1 \pm 4.4$ & $33.9 \pm 29.9$ & $34.5 \pm 2.3$ & $0.24^{*}$ \\
\hline
\end{tabular}

*Student's t-test; **Chi-square test; AIS A: ASIA impairment scale A; FIM ${ }^{\mathrm{TM}} \mathrm{m}$ : motor Functional Independence Measure, FMI c: cognitive Functional Independence Measure. 


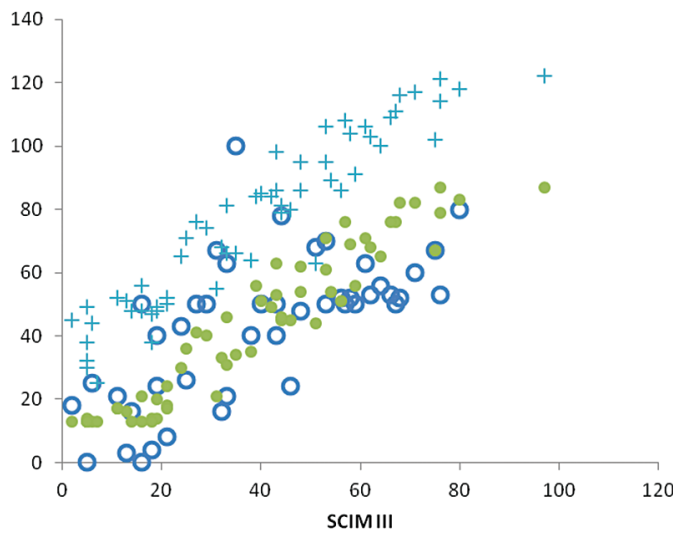

Figure 1. Graph of the dispersion of values of the ASIA motor index (MI), Functional Independence Measure (FIM ${ }^{T M}$ ) motor, and FIM $^{\mathrm{TM}}$ total versus the Spinal Cord Independence Measure (SCIM) III final score.

(0.64), $\mathrm{FIM}^{\mathrm{TM}}$ motor (0.95), and $\mathrm{FIM}^{\mathrm{TM}}$ total (0.94). In contrast, the correlation of the SCIM III with the FIM $^{\mathrm{TM}}$ cognitive (0.37) and with the AIS sensory index (0.33) were very low and are not shown in the Figure 1.

The comparison of the dispersion graphs for the correlation between the SCIM III and the FIM ${ }^{\mathrm{TM}}$ motor instruments from the group of paraplegic and tetraplegic subjects is seen in Figure 2. One can see that many subjects, especially in the tetraplegic group, have a minimum score in the $\mathrm{FIM}^{\mathrm{TM}}$ motor (13), but can still be distinguished at different scoring levels by the SCIM III. At the other end of the curve, at the maximum score in the FIM $^{\mathrm{TM}}$ motor (91), the SCIM III again has a greater discriminative capacity. The Pearson's correlation coefficient between these two instruments was 0.91 for the paraplegic group and 0.94 for the tetraplegic.

After six months, only 37 subjects had been re-evaluated, 26 paraplegic and 11 tetraplegic. Figure 3 expresses the relationship between functioning variation measured by the SCIM III and FIM ${ }^{\mathrm{TM}}$ motor at the end of this period;

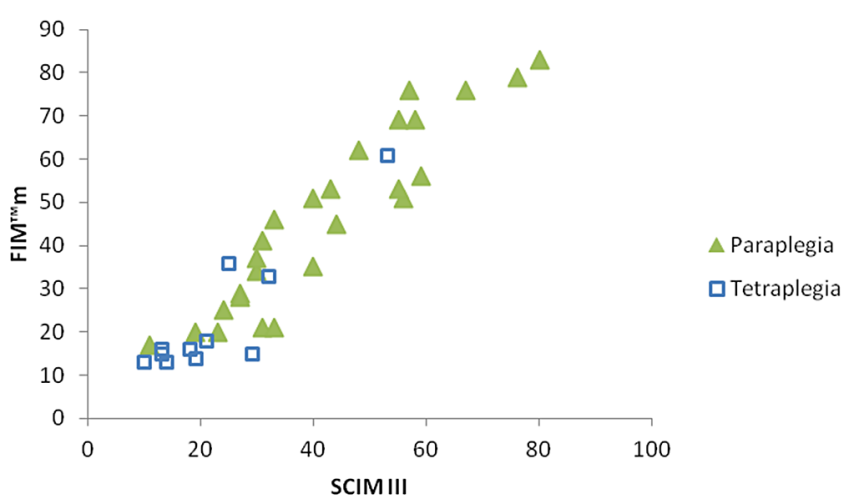

Figure 2. Graph of dispersion of values for Spinal Cord Independence Measure (SCIM) III and motor Functional Independence Measure ( $\left.F I M^{\top M}\right)$ for the paraplegic and tetraplegic groups.

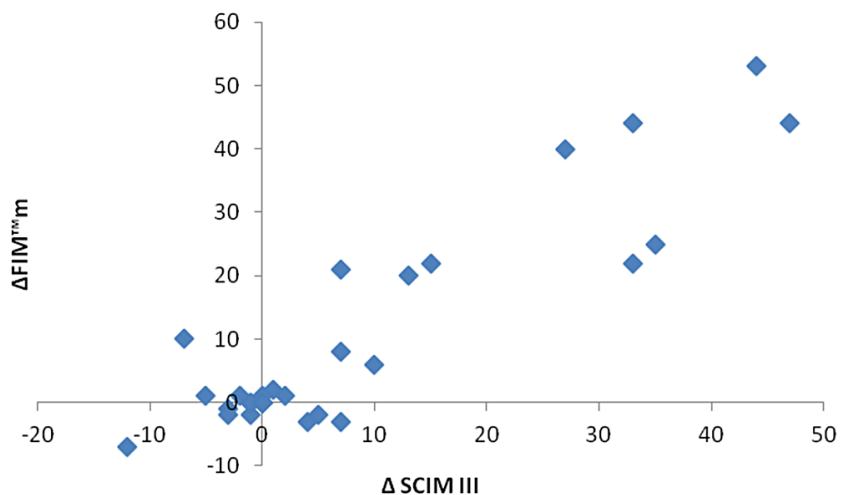

Figure 3. Graph of dispersion of values for functional independence according to the Spinal Cord Independence Measure (SCIM) III and motor Functional Independence Measure $\left(F I M^{\top M}\right)$ at the end of 6 months.

the correlation between these variables was 0.91 , according to the Pearson's coefficient, indicating that the gains observed by one instrument were found in the same proportion by the other.

\section{DISCUSSION}

The objective of this project was to validate the Brazilian version of the SCIM III instrument. This process involved translation of the original English version, as well as testing for reproducibility, and comparison with other questionnaires. We also measured its sensitivity to clinical changes, and its adaptation by Brazilian health professionals with different backgrounds - physicians, nurses, physical therapist and occupational therapists - accustomed to dealing with patients for whom the instrument was designed.

The first goal of this project was fully achieved with the preparation of a Brazilian version with appropriate terminology, easy interpretation, and with its utilization by health professionals who treat individuals with spinal cord injuries. This was made evident by the excellent results for the intraclass correlation coefficient that was calculated for the inter-rater reliability, which was higher than 0.91, indicating fewer errors in assessment (biases). In this case these errors would be inherent to the examiner, to the examinee, or to the instrument itself. Even with an excellent inter-rater reliability index, some factors that could lead to better use were noted.

The first of them, related to the rater, is inexperience in applying the instrument. Unlike the FIM ${ }^{\mathrm{TM}}$, for which there are training courses, the SCIM III has no training courses for examiners in Brazil, for it is not a routine exam in this country. Increased experience by the examiners will most probably lead to more accurate results in the measuring of functioning through this instrument ${ }^{15}$. Professionals who participated in the field study and who were already familiar 
with the FIM $^{\mathrm{TM}}$ pointed out that the SCIM III questions are very easy to interpret and that they are mutually exclusive, which made the instrument easier to apply. Among the factors related to the individual being examined, it can be observed that, due to the short time interval between the raters' evaluations, the memorization of the answers may overestimate the ICC. Finally, some confusion could be associated with subtle differences between the questions in the instrument, which could cause underestimated results.

The high test-retest reproducibility index in question is another parameter that increases the reliability of this instrument. In this case, when the rater applies the instrument again after a short period of a few days, he or she will hardly find any divergences with the first evaluation. However, in this case, it must be considered that short periods of time could lead to overestimation of evaluations from the same rater, since the rater as well as the patient may simply memorize the answers. Nevertheless, to increase the time between the evaluations could underestimate the answers, since the subjects evaluated could answer differently to the same questions due to gains in functioning. The evaluation instruments with higher reproducibility can be advantageous for clinical research, since less variability is expected in the findings stemming from observation, thereby allowing smaller sample sizes to be used ${ }^{16}$.

Observing Table 1, it can be seen that the relationship between the SCIM III total score and the FIM ${ }^{\mathrm{TM}}$ motor partial score and the $\mathrm{FIM}^{\mathrm{TM}}$ total score is positive, tending to a linear relationship. This was expected, especially for the SCIM III and FIM $^{\mathrm{TM}}$ motor relationship, since items such as personal care, sphincters control, transferences, and mobility are investigated by both instruments. In addition, the independence evaluation for cognitive activities via FIM $^{\mathrm{TM}}$ showed a weak correlation (Pearson $=0.37$ ), with a ceiling effect and constant value, which was observed in other samples of individuals with traumatic spinal cord injury ${ }^{14,17}$. Another great difference between the two instruments is that the evaluation of mobility and transference in the SCIM III is more detailed, with items such as mobility inside the house, for moderate distances, and outside the house, as well as transference from the wheelchair to the car and from the floor to the wheelchair. Other important differences are the evaluation of mobility to prevent skin lesions and the independence to breathe.

After this clarification, despite these different approaches, the direct relationship between the results of these instruments corroborates that the SCIM III is a suitable instrument for the motor evaluation of patients with spinal cord injuries. This assertion is reinforced by the Pearson index being close to the maximum value (1, where the relationship is linear and direct): SCIM III x FIM ${ }^{\mathrm{TM}}$ motor (0.95) and FIM ${ }^{\mathrm{TM}}$ total (0.94).
The Pearson correlation coefficient between these two instruments was 0.91 for the paraplegic group and 0.94 for the tetraplegic group. The same correlation coefficients between the SCIM III and the ASIA motor and sensory index are 0.64 and 0.33 . It is observed that although the correlations between the SCIM III and the ASIA indices are positive, they are considerably lower than for other parameters evaluated, since those are concepts different from the functional evaluation, according to the description model of human functionality proposed by the International Classification of Functioning, Disability, and Health ${ }^{18}$.

The dispersion curve for the $\mathrm{FIM}^{\mathrm{TM}}$ motor in paraplegic individuals and the SCIM III index tend to be linear, which does not happen with the FIM $^{\mathrm{TM}}$ motor in tetraplegic individuals, despite the higher Pearson coefficient. Actually, a larger sample would allow the confirmation of a non-linear relationship at the extremes of these curves. For paraplegic individuals the upper extremity of the curve shows that a higher SCIM III score is possible, even if the maximum FIM $^{\mathrm{TM}}$ motor score is reached. This occurs because the SCIM III scores more levels of locomotion and transference, even when the individual already performs this task without any help. It is noteworthy that despite being the standard instrument for functional evaluation of individuals with spinal cord injuries, the FIM $^{\mathrm{TM}}$ shows a ceiling effect that can be overcome by measuring gait with other instruments $^{19}$. However, for tetraplegic individuals, the difference is at the lower extremity of the curve, where the SCIM III can perceive variations for lower scores even if the individual has the lowest FIM ${ }^{\mathrm{TM}}$ score, because only the SCIM III evaluates breathing, which can be severely compromised in persons with these levels of spinal cord injury, compromising their inhaling and coughing independently or even with the use of ventilators ${ }^{20}$.

Figure 3 shows the relationship between the variation of improvement of patients measured by the FIM $^{\mathrm{TM}}$ total and by the SCIM III, where it can be seen that the variation in SCIM III scores is greater than the FIM $^{\mathrm{TM}}$ total variation. This occurs because some functions evaluated by the SCIM III are not evaluated by the $\mathrm{FIM}^{\mathrm{TM}}$ - in this case the breathing item. On the other hand, the $\mathrm{FIM}^{\mathrm{TM}}$ evaluates cognition, while the SCIM III does not. However, as already discussed, cognitive functions usually have no variation among patients with spinal cord injuries. The greatest limitation of this study is the reduced number of observations, since many of the patients included in the study were not re-evaluated at the end of the research. In addition, many of the subjects who participated in this phase of the study were already chronic patients, therefore, with little or no functional improvement, which explains the great concentration of observations close to the apex of the graphic axes. A greater number of observations on patients with variations of functioning could demonstrate a better relationship between these two variables. 
In conclusion, we can state that this Brazilian SCIM III version is easily understood and well accepted by health professionals. It is an instrument with very simple application, guaranteeing a very good reproducibility of the inter- and intra-rater scores. The comparison with another established functional evaluation instrument showed good correlation between the scores. The SCIM III was also sensitive to the functional variations of these individuals. These characteristics bolstered the clinical use of the SCIM III to monitor the functioning and to manage the rehabilitation process of individuals with spinal cord injuries.

\section{Acknowledgements}

Researchers from the spinal cord injury treatment centers who participated in the data collection: Ana Luiza Baptista, Zuila Maria de Figueiredo Carvalho, Kamila Eugênia Paravina Prates, Juliano Aparecido Pires.

\section{References}

1. World Health Organization. International Classification of Functioning, Disability and Health: ICF. WHO: Geneva, 2001.

2. Kirschbeger S, Cieza A, Biering-Sorensen F, et al. ICF core sets for individuals with spinal cord injury in the early post-acute context. Spinal Cord 2010;48:297-304

3. Riberto M, Miyazaki MH, Jorge Filho D, Sakamoto H, Battistella PR. Reprodutibilidade da Medida de Independência Funcional. Acta Fisiatr 2001;8:45-52.

4. Riberto M, Miyazaki MH, Jucá SSH, Sakamoto H, Pinto PPN, Battistella LR. Validação da versão brasileira da Medida de Independência Funcional. Acta Fisiatr 2004;11:72-76.

5. Leonardi M, Martinuzzi A, Meucci P, et al. A population survey in Italy based on the ICF classification: recognizing persons with sereve disability. Sci World J 2012;2012:189097.

6. Vall J, Costa CM, Pereira LF, Friesen TT. Application of International Classification of Functioning, Disability and Haelth (ICF) in individuals with spinal cord injury. Arq Neuropsiquiatr 2011;69:513-518.

7. Post MW, Kirschberger I, Scheuringer M, Wollars MM, Geyh S. Outcome parameters in spinal cord injury research: a systematic review using the International Classification of Functioning, Disability and Health (ICF) as a reference. Spinal Cord 2010;48:522-528.

8. Bampi LNS, Guilhem D, Lima DD. Qualidade de vida em pessoas com lesão medular traumática: um estudo com o WHOQoL-bref. Rev Bras Epidemiol 2008;11:67-77.

9. Stadhouder A, Buckens CFM, Holtslag H, Öner FC. Are existing outcome instruments suitable for assessment of spinal trauma patients? J Neurosurg Spine 2010;13:638-647.

10. Schivoletto G, Tamburella F, Laurenza L, Mollinari M, Ditunno JF. Walking Index for spinal cord injury version II in acute spinal cord injury: reliability and reproducibility. Spinal Cord 2014;52:65-69.

11. Catz A, Itzkovich M, Agranov E, Ring H, Tamir A. SCIM - spinal Cord independence measure: a new disability scale for patients with spinal cord lesions. Spinal cord 1997;35:850-856.
12. Itzkovich M, Gelernter I, Biering-Sorensen F, et al. The spinal cord independence measure (SCIM) version III: reliability and validity in a multi-center international study. Disabil Rehabil 2007;29:1926-1933.

13. Zarco-Periñan MJ, Barrera-Chacón MJ, Garcia-Obrero I, MendezFerrer JB, Alarcon LE, Echevarria-Ruiz de Vargas C. Development of the Spanish version of the Spinal Cord Independence Measure versio III: cross-cultural adaptation and reliability and validity study. Disabil Rehabil 2013 [epub ahead of print].

14. Barbetta DC, Cassemiro LC, Assis MR. The experience of using the scale of Functional Independence Measure in individuals undergoing spinal cord injury rehabilitation in Brazil. Spinal Cord 2014 [epub ahead of print].

15. Tooth LR, Ottembacher KJ. The kappa statistic in rehabilitation research: an examination. Arch Phys Med Rehabil 2004;85:1371-1376.

16. Hayen A, Dennis RJ, Finch CF. Determining the intra- and interobserver reliability of screening tools used in sports medicine. J Sci Med Sport 2007;10:201-210.

17. Ng YS, Jung H, Tay SS, Bok CW, Chiong Y, Lim PAC. Results from a prospective acute inpatient rehabilitation database: clinical characteristics and functional outcomes using the Functional Independence Measure. Ann Acad Med Singapore 2007;36:3-10.

18. Cieza A, Kirchberger I, Biering-Sorensen F, et al. ICF core sets for individuals with spinal cord injury in the long-term context. Spinal Cord 2010;48:305-312.

19. Pramodhyakul W, Wattanapan P, Siritatiwat W, Eunqpinichpong W, Amatachaya S. Immediate effects of obstacle crossing training in independent ambulatory patients with spinal cord injury. Spinal Cord 2010;51:379-383.

20. Brown R, DiMarco AF, Hoit JD, Garshick E. Respiratory dysfunction and management in spinal cord injury. Resp Care 2006;51:853-870. 